\title{
MODEL PILIHAN TRANSJAKARTA DENGAN PERBAIKAN WAKTU TEMPUH PENGGUNA JALAN GAJAH MADA DENGAN PENERAPAN ERP
}

\author{
Rini Martini' ${ }^{1}$ dan Najid $^{2}$ \\ ${ }^{1}$ Program Studi Sarjana Teknik Sipil, Universitas Tarumanagara, Jl. Letjen S. Parman No.1 Jakarta \\ rini.325160171@stu.untar.ac.id \\ ${ }^{2}$ Program Studi Sarjana Teknik Sipil, Universitas Tarumanagara, Jl. Letjen S. Parman No.1 Jakarta \\ najid@ft.untar.ac.id
}

Masuk: 05-07-2020, revisi: 31-07-2020, diterima untuk diterbitkan: 31-07-2020

\begin{abstract}
Transjakarta is one of the public transportation facility provided by Indonesian government to decrease of the traffic in Jakarta, but when this government is planning to implement new traffic rules ERP (Electronic Road Pricing) or streed paid. In this study, will be discussed about the condition on jl. Gajah Mada, segment road is an access to the road towards the center of the shopping and office. To analyze the volume of vehicles will be used method of observation directly to obtain the volume, speed and traffic density. Direct observation is done by paying attention to private vehicles and heavy vehicles. With the observation data will get a graph of the relationship between speed and density that will be modified eith questionnaire data. Questionnaire data is distributed to get the percentage of Transjakarta with feeder total round trip cost with travel time. In this study it is expected to know the percentage of private vehicle users who will switch to Transjakarta with their feeders after the ERP (Electronic Road Pricing) implemented on the Gajah Mada street.
\end{abstract}

Keywords: Gajah Mada; Transjakarta; ERP

\begin{abstract}
ABSTRAK
Transjakarta yakni salah satu sarana transportasi publik yang diberikan pemerintah Indonesia untuk mengatasi kepadatan lalu lintas di Jakarta, namun saat ini pemerintah berencana untuk menerapkan aturan lalu lintas baru yaitu ERP (Electronic Road Pricing) atau jalan berbayar. Pada penelitian ini akan dibahas mengenai kondisi lalu lintas Jl. Gajah Mada, ruas jalan ini merupakan akses pengguna jalan untuk menuju pusat perbelanjaan dan perkantoran. Untuk menganalisa volume kendaraan akan digunakan metode observasi langsung untuk mendapatkan volume, kecepatan dan kepadatan lalu lintas. Observasi langsung dilakukan dengan memperhatikan kendaraan bermotor roda empat dan dua serta kendaraan berat. Dengan data observasi akan didapat grafik hubungan antara kecepatan dan kepadatan yang akan dimodifikasi dengan data kuesioner. Data kuesioner disebar untuk mendapatkan presentase perbaikan total biaya pulang-pergi dengan waktu tempuh bus Transjakarta dengan feedernya. Pada penelitian ini diharapkan dapat mengetahui presentase pengguna kendaraan pribadi yang akan beralih ke Transjakarta dengan feedernya setelah diberlakukannya ERP (Electronic Road Pricing) di ruas Jalan Gajah Mada.
\end{abstract}

Kata kunci: Gajah Mada; Transjakarta; ERP

\section{PENDAHULUAN}

Indonesia merupakan salah satu Negara berkembang dengan jumlah penduduk terbanyak ke 4 di dunia. Seperti halnya negara berkembang lain, Indonesia memiliki tingkat urbanisai tinggi khususnya di kota-kota besar, seperti kota Jakarta. Jumlah penduduk DKI Jakarta saat ini mencapai 10,6 juta jiwa. Jumlah tersebut akan terus bertambah dari tahun ke tahun. Hal ini berdampak kepada tingginya keperluan masyarakat kota Jakarta akan transportasi, guna mendukung kebutuhan masyarakat dalam menjalankan kegiatanya sehari-hari. Dengan terus bertambahnya jumlah penduduk di kota Jakarta, hal yang menjadi kebutuhan utama dari masyarakat kota Jakarta adalah kebutuhan kendaraan bermotor. Hal ini menyebabkan kepadatan lalu lintas yang menimbulkan kemacetan.

Masalah utama kepadatan lalu lintas di Jakarta adalah jumlah kendaraan yang terlalu banyak jika dibandingkan dengan ruas jalan yang tersedia. Masalah tersebut semakin diperparah lagi dengan bertambahnya masyarakat yang lebih memilih menggunakan kendaraan pribadi untuk melakukan setiap kegiatannya, dikarenakan menggunakan transportasi pribadi sangatlah memungkinkan untuk setiap orang lebih dinamis jika menggunakan transportasi umum. 
Pemprov DKI Jakarta terus melakukan berbagai cara dan upaya untuk mengurangi kemacetan, salah satunya dengan mengatur jumlah penduduk non-Jakarta yang mencari kehidupan di kota Jakarta. Selain itu pemprov DKI Jakarta berupaya untuk mengubah pola pikir masyarakat yang asalnya berorientasi pada pengguaan kendaraan pribadi dan beralih kepada orientasi penggunaan sarana transportasi publik khususnya Transjakarta. Transjakarta yang didalamnya mempunyai banyak kelebihan jika dibandingkan dengan penggunaan kendaraan pribadi. Akan tetapi dibalik semua kelebihan tersebut, Transjakarta juga mempunyai kekurangan. Dengan penerapan ERP (Electronic Road Pricing) adalah Salah satu alternatif untuk mengatasi masalah ini.

Sehubungan dengan masih banyaknya masyarakat Jakarta yang menggunakan kendaraan pribadi dibandingkan dengan kendaran umum transjakarta, maka dibutuhkan faktor-faktor apa yang mempengaruhinya, dengan melihat bagaimana karakteristik permintaan transjakarta. Dan dengan melihat penelitian sebelumnya, tentang angka dan kapasitas biaya ERP penelitian ini diharapkan dapat mengetahui seberapa jauh pengaruh ERP terhadap permintaan penumpang transjakarta dan pengaruh ERP terhadap kinerja lalu lintas apabila ERP diterapkan di jalan Gajah Mada, Jakarta Pusat.

\section{Kapasitas jalan}

Menurut Abubakar (2012), kapasitas jalan merupakan efisiensi ruas jalan yang sempurna dalam satuan waktu tertentu untuk menangkal arus atau volume lalu lintas, dalam satuan jam (kend/jam) yang dinyatakan dalam jumlah kendaraan yang melewati potongan jalan tertentu atau dengan memperhitungkan berbagai jenis kendaraan yang melalui suatu jalan di gunakan satuan mobil penumpang sebagai satuan kendaraan dalam perhitungan kapasitas maka kapasitas menggunakan satuan mobil penumpang per jam atau (smp)/jam.

Ketika arus rendah kecepatan arus lalu lintas kendaraan bebas, tidak ada hambatan dari kendaraan lain, kapasitas terjadi ketika semakin banyak kendaraan yang melewati ruas jalan kecepatan akan semakin turun hingga suatu saat tidak bisa lagi arus atau volume lalu lintas bertambah. Kemudian dalam keadaan arus yang dipaksakan hingga suatu saat kondisi macet total arus akan berkurang terus, arus tidak bergerak dan kepadatan tinggi sehingga menyebabkan kemacetan.

\section{Hubungan volume dengan kecepatan dan kepadatan}

Menurut Rompis dan Jansen (2019), volume lalu lintas adalah hubungan antara kendaraan, jalan dan pengemudi. Pada kondisi yang sama tidak ada volume lalu lintas yang serupa, sehingga selalu beraneka ragam arus pada suatu ruas jalan tertentu.

Hubungan antara arus volume lalu lintas kecepatan dengan kepadatan lalu lintas dapat dilihat pada gambar sebagai berikut:

1. Hubungan antara kecepatan dengan arus

Hubungan antara kecepatan dengan arus yaitu parabola yang menyajikan bahwa semakin besar arus, kecepatan akan turun sampai suatu titik yang menjadi puncak parabola tercapai kinerja setelah itu kecepatan akan semakin rendah lagi dan arus juga akan semakin kecil dapat dilihat pada gambar 1.

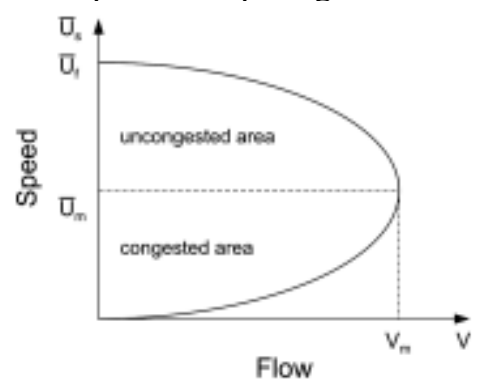

Gambar 1. Hubungan antara arus dengaan kecepatan (Sumber: Manual Kapasitas Jalan Indonesia, 1997)

2. Hubungan antara kecepatan dengan kepadatan

Hubungan antara kecepatan dengan kepadatan merupakan linear yang dapat diartikan bahwa semakin tinggi kecepatan lalu lintas, maka diperlukan ruang bebas yang lebih besar antara kendaraan, yang menyebabkan menjadi lebih kecil jumlah kendaraan perkilometer dapat dilihat pada gambar 2. 


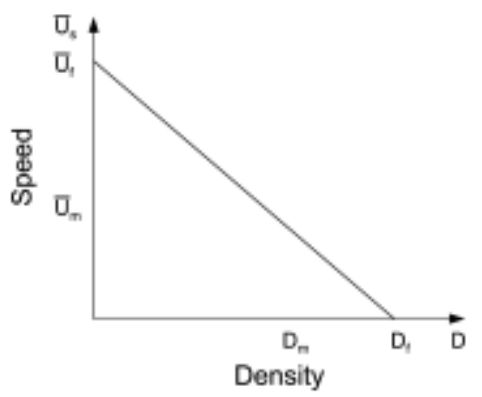

Gambar 2. Hubungan antara kecepatan dengan kepadatan (Sumber: Manual Kapasitas Jalan Indonesia, 1997)

3. Hubungan antara volume dengan kepadatan

Hubungan antara volume dengan lalu lintas juga parabolik yaitu semakin tinggi kepadatan sampai pada titik dimana kapasitas terjadi serta semakin padat maka arus akan semakin kecil dapat dilihat pada gambar 3.

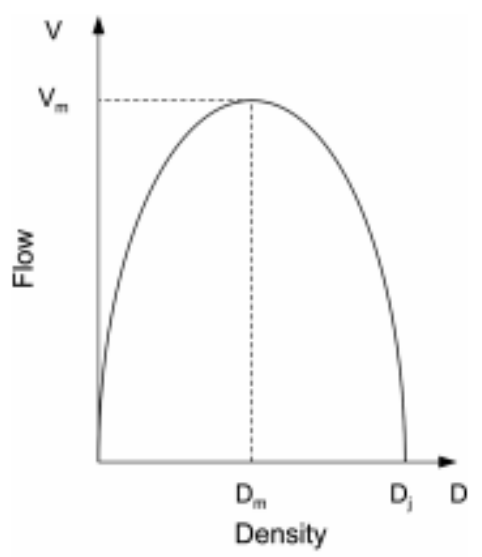

Gambar 3. Hubungan antara arus dengan kepadatan (Sumber: Manual Kapasitas Jalan Indonesia, 1997)

\section{Transjakarta}

Menurut Saksono, Darmaningtyas dan Waro (2012), sebuah sistem transportasi Bus Rapid Transit (BRT) pertama di Asia Tenggara dan Selatan yang berjalan mulai dari tahun 2004 di Jakarta, Indonesia disebut Transjakarta. Transjakarta didesain sebagai moda transportasi massal penganut aktivitas kemacetan di ibukota. Dengan jalur lintasan terpanjang di dunia $(251,2 \mathrm{~km})$, dan memiliki 260 halte yang tersebar dalam 13 koridor, Transjakarta yang awalnya beroperasi mulai pukul 05.00-22.00 WIB, saat ini beroperasi 24 jam. Sistem BRT ini dirancang berlandasan sistem transmilenio di Bogota, Kolombia.

Menurut Herbowo (2012), Ciri-ciri utama Bus Rapid Transit meliputi: stasiun dan terminal yang bersih, aman dan nyaman, penarikan biaya sebelum berangkat yang efektif, jalur bus terpisah naik dan turun kendaraan yang cepat, penataan yang jelas dan mudah diingat dan tampilan informasi yang serentak, pengutamaan angkutan dipersimpangan, integrasi moda di stasiun dan terminal, teknologi bus yang bersih dan identitas pemasaran yang canggih.

Menurut Susilo dan Leontan (2012), Bus yang digunakan sebagai bus Transjakarta pada umumnya adalah Bus Mercedes-Benz dan Hino dengan warna bus adalah merh dan kuning dan bahan bakar yang dipakai adalah biosolar. Disbanding dengan bus lain, bus Transjakarta mempunyai pintu yang terletak lebih tinggi sehingga hanya dapat ditumpangi dari halte khusus busway (shelter). Menerapkan sistem lipat otomatis yang dapat dikendalikan dari konsol yang ada di panel pengemudi, pintu tersebut terletak dibagian tengah kanan dan kiri dengan.

\section{Electronic road pricing}

ERP (Electronic Road Pricing) merupakan sistem jalan berbayar yang diterapkan secara elektronik. Sistem ini diterapkan pada ruas jalan yang padat atau macet dan menggunakan tarif progresif. Pada saat sibuk dan saat padat akan dikenakan tarif yang lebih tinggi dibandingkan dengan waktu kosong. Berbagai Negara seperti Singapura, Jepang, Malaysia, dan Inggris yang sudah menerapkan Sistem jalan berbayar ini. Secara umum ERP adalah manajemen permintaan perjalanan (Travel Demand Management) yang bertujuan untuk mengajak pengguna jalan 
agar dapat meminimalisir perjalanan lalu lintas yang relatif tidak perlu dan mengajak pengguna moda transportasi yang ramah lingkungan lebih efisien dan lebih sehat.

Menurut Susanto (2008) Kebijakan Travel Demand Management dapat dibagi menjadi tiga group, yaitu: instrumeninstrumen regulasi (regulation instruments), persetujuan-persetujuan kerjasama (cooperative agreements), dan instrumen-instrumen ekonomi (economic instruments). Congestion pricing (pungutan biaya kemacetan) merupakan salah satu economic instrument yang bertujuan untuk mengurangi penggunaan kendaraan pribadi. Untuk cara kerja ERP dapat dilihat pada gambar 4.

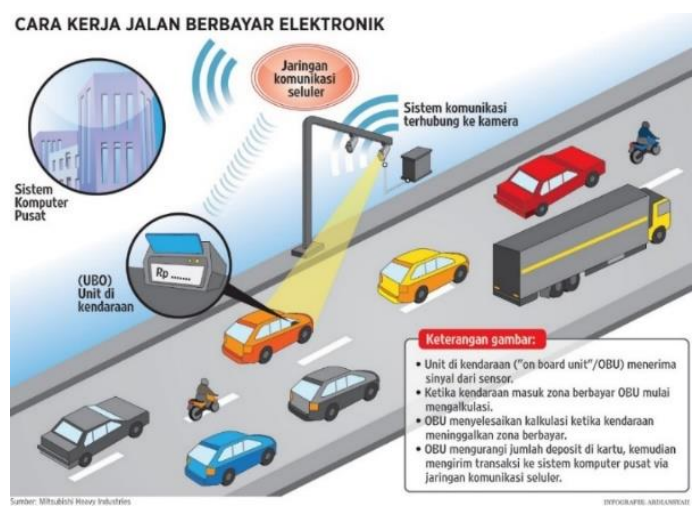

Gambar 4. Cara kerja OBU (On Board Unit) (Sumber: mitsubisi heavy industries)

\section{Stated preference}

Menurut Putra (2015), metode ini dapat melihat atau memprediksi bagaimana tanggapan mereka terhadap peraturan baru atau bagaimana masyarakat memilih moda perjalanan yang belum sehingga stated preference telah secara luas diperkenankan dalam bidang transportasi. Untuk mengambil keputusan alternatif rancangan yang terbaik dari beberapa macam pilihan rancangan stated preference ini menggunakan pernyataan preferensi dari para responden. Teknik ini mendasarkan perkiraan permintaan pada sebuah analisis respon terhadap pilihan yang sifatnya hipotetikal misalnya sarana yang masih dalam perencanaan. Hal ini tentu saja dapat melingkupi atribut-atribut dan hal-hal dalam lingkup yang lebih luas daripada sistem yang sifatnya nyata.

\section{METODE PENELITIAN}

\section{Tahapan penelitian}

Lokasi penelitian ini berada di ruas jalan Gajah Mada Jakarta pusat. Pada awalnya penelitian ini akan mendapatkan data dengan metode observasi langsung kemudian metode wawancara atau angket kuesioner dengan metode stated preference. Pada metode observasi langsung di ruas jalan Gajah Mada akan didapatkan data kapasitas dan hambatan samping.

Kemudian akan diidentifikasi masalah yang telah ada, lalu dilakukan pembuatan formulir survei yang akan di uji coba sebelum disebarkan formulir survei sebagai kuesioner akhir. Data yang akan diambil yaitu data primer dari hasil observasi langsung dan kuesioner. Data kuesioner berupa data penduduk yang akan pindah dari transportasi pribadi atau transportasi online ke Transjakarta. Dari data primer yang ada kemudian akan di analisa.

\section{Metode penelitian}

Berikut merupakan metode yang digunakan dalam penelitian ini yaitu:

1. Studi literatur yaitu dengan menggali acuan teori yang relafan dengan peristiwa atau kejadian yang ditemukan. Acuan-acuan ini dapat di cari dari artikel laporan penelitian, skripsi terdahulu, buku, jurnal, situs-situs internet yang berhubungan dengan yang akan dibahas.

2. Survei dengan metode pendekatan

3. Metode survei pada jalan yang ditinjau dengan cara memperhatikan jumlah kendaraan yang lewat dalam kurun waktu kurang lebih satu jam.

4. Menganalisis data pengamatan dengan membuat model transportasi dan grafik hubungan antara volume, kecepatan dan kepadatan.

5. Menganalisis data kuesioner dan dilihat harga berapa terjadi kecepatan dan kapasitas yang efisien. 


\section{Metode pengumpulan data}

Metode pengumpulan data adalah teknik atau cara yang dilakukan untuk mengumpulkan data. Hal ini merupakan bagian penting yang harus dilakukan dalam penelitian. Data yang diperoleh dalam penelitian ini berupa data observasi lapangan yang dilakukan dengan cara peninjauan langsung di lokasi penelitian. Data-data yang dihasilkan meliputi kapasitas jalan, kecepatan, kepadatan dan volume lalu lintas. Selain data observasi lapangan, adapun data yang diperoleh yaitu data kuesioner.

Kuesioner adalah teknik pengumpulan data yang dilakukan dengan cara memberi seperangkat pertanyaan tertulis kepada responden. Kuesioner ada dua, yaitu kuesioner tertutup dan keusioner terbuka. Dalam penelitian ini keusioner yang tertutup yang digunakan yakni kuesioner yang sudah ada pilihanya, kemudian responden tinggal menjawab dan memilih secara langsung. Kuesioner ini dilakukan untuk mengetahui persepsi responden tentang transjakarta di Gajah Mada.

\section{Metode wawancara kuesioner}

Menurut Harianto (2016) wawancara merupakan salah satu teknik pengumpulan data yang dilakukan melewati tatap muka dan tanya jawab secara langsung antara pengumpul data maupun peneliti kepada narasumber atau sumber data. Karena tidak mungkin menggunakan wawancara pada 1000 responden wawancara penelitian sampel besar umumnya hanya dilakukan sebagai studi pendahuluan, sebaliknya dapat diterapkan sebagai teknik pengumpulan data (umumnya penelitian kualitatif) pada sampel kecil teknik wawancara. Ada dua jenis wawancara, Yaitu sebagai berikut:

1. Wawancara terstruktur yaitu dapat diartikan bahwa peneliti telah mengetahui yakni apa informasi yang ingin digali dari responden sehingga pertanyaannya sudah dibuat secara terstruktur. Peneliti juga dapat dibantu dengan menggunakan alat bantu tape recorder, kamera photo dan material lain yang agar memudahkan dalam kelancaran wawancara.

2. Wawancara tidak terstruktur atau wawancara bebas, yaitu dari responden peneliti hanya menampung poin-poin penting masalah yang ingin digali tidak menggunakan dasar-dasar wawancara yang berisi pertanyaan yang akan diajukan secara spesifik.

Kuesioner adalah teknik pengumpulan data yaitu dengan cara memberikan seperangkat pernyataan atau pertanyaan kepada orang yang dijadikan responden untuk dijawabnya. Meskipun terlihat mudah, teknik pengumpulan data melalui kuesioner cukup sulit dilakukan jika respondennya cukup besar dan tersebar di beragam wilayah. Beberapa hal yang perlu diperhatikan dalam pembuatan kuesioner terkait dengan prinsip penulisan kuesioner, prinsip pengukuran dan penampilan fisik.

1. Isi dan tujuan pertanyaan yakni harus ada skala yang jelas dalam pilihan jawaban jika pertanyaan ditunjukan untuk memperkirakan.

2. Bahasa yang digunakan harus disesuaikan dengan kesanggupan responden. Tidak mungkin menggunakan bahasa yang penuh sebutan-sebutan bahasa inggris pada responden yang tidak paham bahasa inggris dan sebagainya.

3. Jika tipe dan bentuk pertanyaan terbuka artinya jawaban yang diberikan adalah bebas, sedangkan jika pertanyaan tertutup maka responden hanya diminta untuk memilih jawaban yang disediakan.

\section{Metode regresi linear berganda}

Regresi linear adalah metode statistika yang digunakan untuk membuat model hubungan antara variabel terikat (dependen; responden; Y) dengan satu atau lebih variabel bebas (independen; prediktor; X). Analisis regresi setidaknya memiliki 3 kegunaan, yaitu untuk tujuan deskripsi dari fenomena data atau kasus yang sedang diteliti, untuk tujuan pengamatan, serta untuk tujuan prediksi.

Dari variabel-variabel bebas yang digunakan untuk membentuk model regresi tersebut, bentuk persamaan regresi linear sebagai berikut:

Keterangan:

$$
\begin{aligned}
& b=\frac{\left(n \cdot \sum x y\right)-\left(\sum x \cdot \sum y\right)}{\left(n \cdot \sum x^{2}\right)-\left(\sum x \cdot \sum y\right)} \\
& a=\frac{\sum y}{n}-\frac{b \cdot \sum x}{n} \\
& Y=a+b \cdot X
\end{aligned}
$$

Y : variabel hasil prediksi,

a : konstanta kurva linear,

b : koefisien parameter laju,

$\mathrm{X}$ : pertumbuhan beban variabel dan

$\mathrm{n} \quad$ : jumlah data 
Regresi linear sederhana yaitu Jika banyaknya variabel bebas hanya ada satu, sedangkan regresi linear berganda yaitu apabila terdapat lebih dari 1 variabel bebas. Analisis ini untuk mendapatkan arah hubungan antara variabel independen dengan variabel dependen apakah masing-masing variabel independen berhubungan positif atau negatif dan untuk memprediksi nilai dari variabel dependen apabila nilai variabel independen mengalami kenaikan atau penurunan. Data yang digunakan biasanya berskala interval atau rasio. (Regresi)

Persamaan linear berganda, yaitu sebagai berikut:

$$
\mathrm{Y}^{\prime}=\mathrm{A}+\mathrm{b}_{1} \mathrm{X}_{1}+\mathrm{b}_{2} \mathrm{X}_{2}+\ldots .+\mathrm{b}_{\mathrm{n}} \mathrm{X}_{\mathrm{n}}
$$

Keterangan:

$\begin{array}{ll}\mathrm{Y}^{\prime} & : \text { Variabel dependen (nilai yang diprediksi) } \\ \mathrm{X}_{1} \text { dan } \mathrm{X}_{2} & : \text { Variabel independen } \\ \mathrm{a} & : \text { Konstanta (nilai } \mathrm{Y}^{\prime} \text { apabila } \mathrm{X}_{1}, \mathrm{X}_{2}, \ldots \ldots \mathrm{X}_{\mathrm{n}}=0 \text { ) } \\ \mathrm{b} & : \text { koefisien regresi (nilai peningkatan ataupun penurunan) }\end{array}$

\section{HASIL DAN PEMBAHASAN}

\section{Tabulasi data}

Tabulasi data perbaikan waktu tempuh Transjakarta dapat dilihat pada tabel 1, yaitu sebagai berikut:

Tabel 1. Tabulasi data perbaikan waktu tempuh transjakarta

\begin{tabular}{|c|c|c|c|c|c|}
\hline No & $\begin{array}{c}\text { Perbaikan Waktu Tempuh } \\
\text { Transjakarta dengan Feedernya }\end{array}$ & 1 & 2 & 3 & 4 \\
\hline 1 & $\begin{array}{l}\text { Total tarif (pergi-pulang) Rp. 25.000- } \\
\text { Rp. } 30.000 \text {, waktu tempuh lebih cepat } \\
\text { 25-30 menit (Pelayanan Lainnya sama } \\
\text { dengan kondisi saat ini) }\end{array}$ & 21 & 25 & 4 & 0 \\
\hline 2 & $\begin{array}{l}\text { Total tarif (pergi-pulang) Rp. 20.000- } \\
\text { Rp. } 25.000 \text {, waktu tempuh lebih cepat } \\
\text { 20-25 menit (Pelayanan Lainnya sama } \\
\text { dengan kondisi saat ini) }\end{array}$ & 0 & 34 & 16 & 0 \\
\hline 3 & $\begin{array}{l}\text { Total tarif (pergi-pulang) Rp. 15.000- } \\
\text { Rp. } 20.000 \text {, waktu tempuh lebih cepat } \\
\text { 10-20 menit (Pelayanan Lainnya sama } \\
\text { dengan kondisi saat ini) }\end{array}$ & 0 & 1 & 39 & 10 \\
\hline 4 & $\begin{array}{c}\text { Total tarif (pergi-pulang) Rp. 10.000- } \\
\text { Rp. } 15.000 \text {, waktu tempuh lebih cepat } \\
\text { 5-10 menit (Pelayanan Lainnya sama } \\
\text { dengan kondisi saat ini) }\end{array}$ & 0 & 0 & 34 & 16 \\
\hline 5 & $\begin{array}{l}\text { Total tarif (pergi-pulang) Rp. 5.000- } \\
\text { Rp. } 10.000 \text { (Pelayanan Lainnya sama } \\
\text { dengan kondisi saat ini) }\end{array}$ & 0 & 6 & 22 & 22 \\
\hline
\end{tabular}

Dapat dilihat bahwa responden lebih dominan menjawab pilihan dengan biaya pulang-pergi Rp.5.000 - Rp.10.000, Rp.10.000 - Rp.15.000 waktu tempuh lebih cepat 5-10 menit dan Rp.15.000 - Rp.20.000, waktu tempuh lebih cepat 10-20 menit. 


\section{Data hasil jawaban kuesioner pemilihan perbaikan waktu tempuh transjakarta dengan feedernya}

Data hasil jawaban kuesioner dapat dilihat pada gambar sebai berikut:

1. Data jawaban responden untuk total tarif (pergi-pulang) Rp. 25.000-Rp. 30.000, waktu tempuh lebih cepat 2530 menit dapat dilihat pada gambar 5.

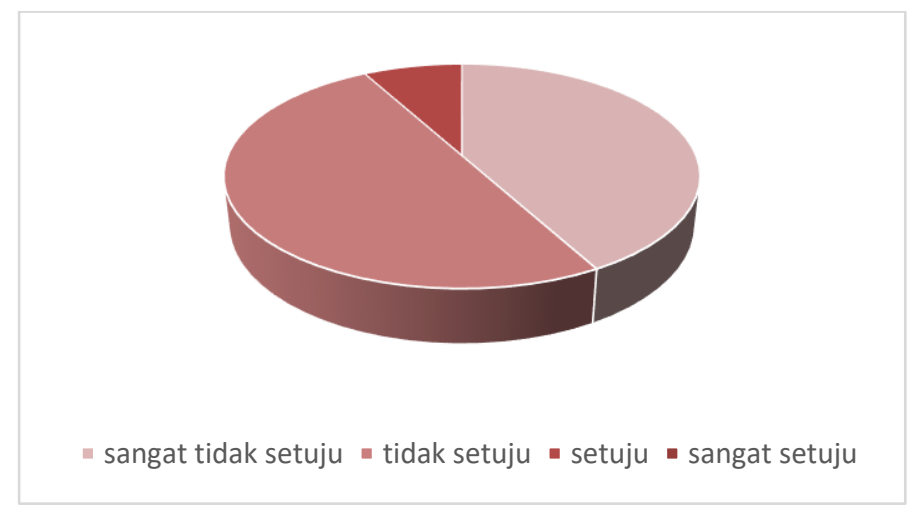

Gambar 5. Data pilihan responden untuk total tarif (pergi-pulang) Rp. 25.000-Rp. 30.000, waktu tempuh lebih cepat 25-30 menit

2. Data jawaban responden untuk total tarif (pergi-pulang) Rp. 20.000-Rp. 25.000, waktu tempuh lebih cepat 2025 menit dapat dilihat pada gambar 6 .

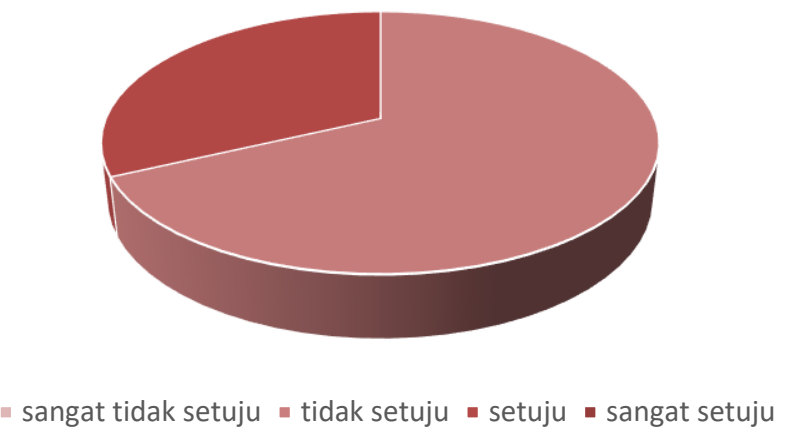

Gambar 6. Data pilihan responden untuk total tarif (pergi-pulang) Rp. 20.000-Rp. 25.000, waktu tempuh lebih cepat 20-25 menit

3. Data jawaban responden untuk total tarif (pergi-pulang) Rp. 15.000-Rp. 20.000, waktu tempuh lebih cepat 1020 menit dapat dilihat pada gambar 7.

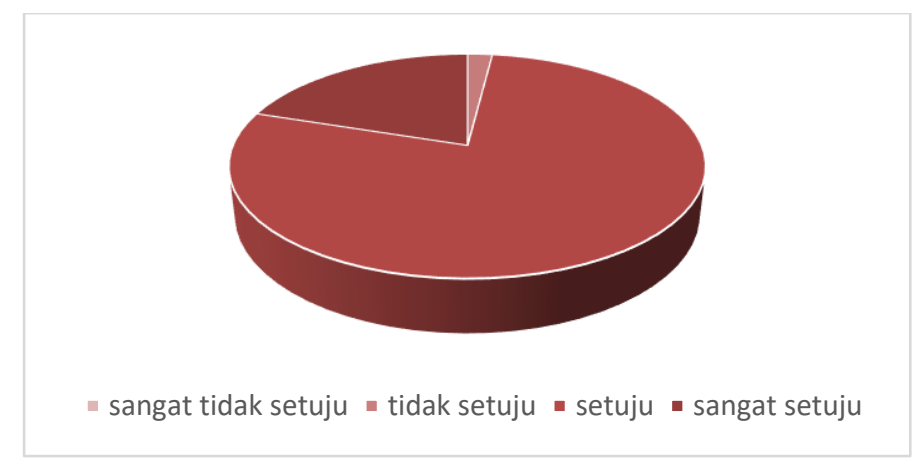

Gambar 7. Data pilihan responden untuk total tarif (pergi-pulang) Rp. 15.000-Rp. 20.000, waktu tempuh lebih cepat 10-20 menit 
4. Data jawaban responden untuk total tarif (pergi-pulang) Rp. 10.000-Rp. 15.000, waktu tempuh lebih cepat 5-10 menit dapat dilihat pada gambar 8.

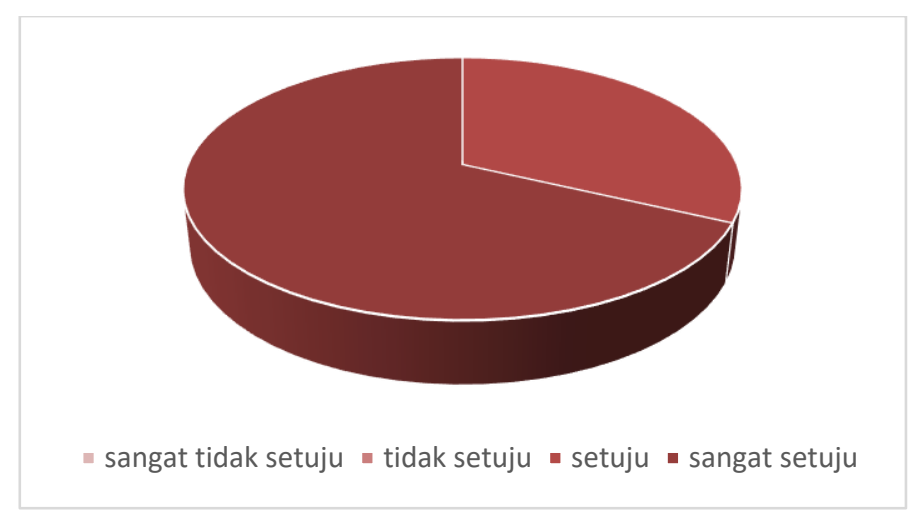

Gambar 8. Data pilihan responden untuk total tarif (pergi-pulang) Rp. 10.000-Rp. 15.000, waktu tempuh lebih cepat 5-10 menit

5. Data jawaban responden untuk total tarif (pergi-pulang) Rp. 5.000-Rp. 10.000 (Pelayanan Lainnya sama dengan kondisi saat ini) dapat dilihat pada gambar 9.

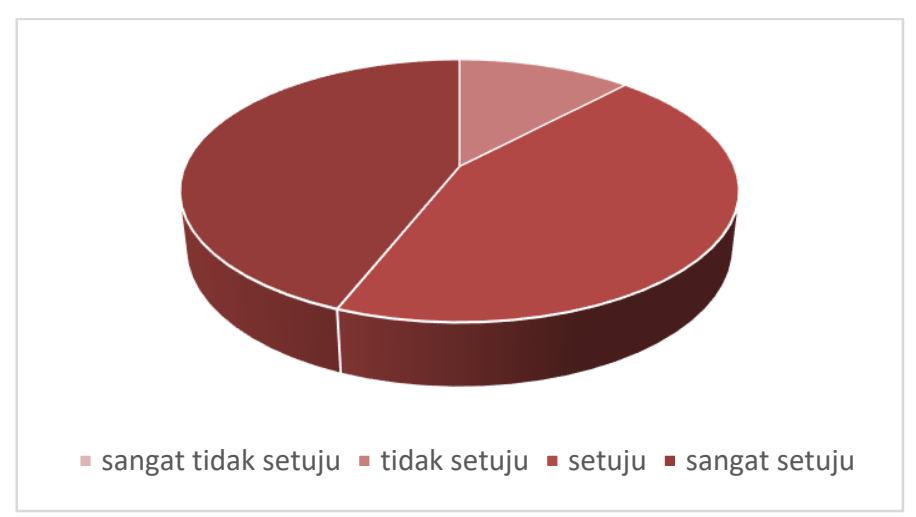

Gambar 9. Data pilihan responden untuk total tarif (pergi-pulang) Rp. 5.000-Rp. 10.000 (Pelayanan Lainnya sama dengan kondisi saat ini)

\section{Analisis data kuesioner}

Data hasil penyebaran kuesioner yang dilakukan secara online melalui sosial media yang dikumpulkan kemudian akan dianalisis dengan menggunakan metode analisis statistik metode regresi dan didapatkan persamaan sebagai berikut.

$$
\mathrm{Y}=0,0085-0,0735 . \mathrm{X} 1-0,2032 . \mathrm{X} 2
$$

Variabel X1 menunjukan harga dan X2 menunjukan waktu untuk perbaikan Transjakarta dengan feedernya. Model ini dapat dilihat pada tabel 2.

Tabel 2. Model

\begin{tabular}{|c|c|c|c|}
\hline \multicolumn{4}{|c|}{$Y=0,0085-0,0735 \cdot X 1-0,2032 \cdot X 2$} \\
\hline Y1 & $\mathrm{X} 1$ & $\mathrm{X} 2$ & $\mathrm{Y}$ \\
\hline 0,0085 & 30 & -25 & 7,285 \\
\hline 0,0085 & 25 & -20 & 5,9015 \\
\hline 0,0085 & 20 & -10 & 3,502 \\
\hline 0,0085 & 15 & -5 & 2,1185 \\
\hline 0,0085 & 10 & 0 & 0,735 \\
\hline
\end{tabular}




\section{KESIMPULAN DAN SARAN}

\section{Kesimpulan}

Berdasarkan penelitian yang telah dilakukan, maka diperoleh beberapa kesimpulan berikut:

1. Dilihat dari hasil kuesioner yang telah disebar secara online kepada responden dapat diketahui bahwa responden lebih cenderung memilih total biaya Rp.15.000 - Rp.20.000 dengan waktu tempuh lebih cepat 10 - 20 menit dan Rp.10.000 - Rp.15.000 dengan waktu tempuh lebih cepat 5-10 menit untuk perbaikan waktu tempuh Transjakarta dengan feedernya. Hal ini dapat disimpulkan bahwa responden telah mengurangi penggunaan kendaraan pribadi dan telah berpindah menggunakan Transjakarta dan feedernya.

2. Dari hasil kuesioner yang telah disebar secara online kepada responden dapat diketahui bahwa dengan diterapkannya ERP (Electronic Road Pricing) di ruas jalan Gajah Mada, 13\% responden telah berpindah ke Transjakarta dengan feedernya. Sisanya dari analisis yang sudah dihitung, dengan cara memperbaiki waktu tempuh dengan biaya yang lebih tinggi untuk Transjakarta $20 \%$ responden berpindah dari kendaraan pribadi ke Transjakarta koridor 1.

3. Dari hasil analisis statistik yang sudah dihitung didapatkan model $\mathrm{Y}=0,0085-0,0735 . \mathrm{X} 1-0,2032 . \mathrm{X} 2 \mathrm{hal}$ ini diketahui bahwa $\mathrm{X} 1$ dan $\mathrm{X} 2$ berpengaruh terhadap $\mathrm{Y}$ dengan $\mathrm{X} 1$ yaitu biaya dan $\mathrm{X} 2$ yaitu waktu tempuh

\section{Saran}

Berikut beberapa saran yang dapat disampaikan untuk penelitian selanjutnya:

1. Berdasarkan Penelitian yang sama perlu dilakukan pada ruas-ruas jalan yang berbeda.

2. Penelitian pada ruas jalan yang sama perlu dilakukan perbaikan pelayanan Transjakarta yang berbeda.

\section{DAFTAR PUSTAKA}

Abubakar, Iskandar. "Manajemen Lalu Lintas". jakarta: TRANSINDO Gastama Media, 2012.

Marga, Direktorat Jendral Bina. "Manual Kapasitas Jalan Indonesia". 1997.

Putra , Agung Nugroho. “Stated Preference Kebutuhan Angkutan”. (2015). Web. 7 Juni. 2020.

Rompis, Semuel Y.R. dan Freddy Jansen. "Pengaruh Penerapan Road Pricing Pada Ruas Jalan”. Sipil Statik (2019): 103-112. Web. 23 Juni. 2020.

Senapati, Randy. "Pengaruh Electronic Road Pricing Terhadap Volume Lalu Lintas Pada Ruas Blok M-Kota.”(2020).

Saksono, Bani, Darmaningtyas dan Achmad Izzul Waro. Manajemen Transjakarta Busway. Jakarta: Transindo Gastama Media, 2012.

Susantono, Bambang. "Electronic Road Pricing (ERP) Salah Satu Solusi Masalah Kemacetan di Kota Jakarta". Jakarta: Buletin Tata Ruang, 2008. Web. 23 Februari. 2020.

Susilo, Budi Hartanto dan Apriyanto Leontan. "Kajian Operasi Bus Rapid Transit Transjakarta dan Transmilenio Bogota”. (2007). Web 23 Juni. 2020. 
